\title{
Performance analysis of a pressure swing adsorption unit in removing biogas impurities using zeolite $13 \mathrm{X}$
}

\author{
Magomnang Antonio-Abdu Sami ${ }^{1}$, Villanueva Eliseo $^{2}$ \\ ${ }_{1,2}$ Mechanical Engineering Department, College of Engineering and Architecture, University of Science and Technology of Southern \\ Philippines - Cagayan de Oro Campus, Cagayan de Oro City, Philippines \\ ${ }^{2}$ Mechanical Engineering Department, College of Engineering, MSU-Iligan Institute of Technology, Tibanga, Iligan City, Philippines
}

\begin{abstract}
This study aims to assess the performance of a Pressure Swing Adsorption (PSA) unit in removing the carbon dioxide from biogas by evaluating the breakthrough and adsorption capacity of the adsorption process as well as determining the effects of cyclic regeneration of the adsorbent. The PSA system developed and composed only a main vessel made up of 316 stainless steel components. It was then operated up to 10 bars pressure at ambient temperatures and gas flows at a rate from 0 to $15 \mathrm{~L} \mathrm{~min}^{-1}$. Use of physical adsorbent (zeolite 13X) will consume the gaseous impurities such as $\mathrm{CO}_{2}$. Product gas was collected into $1 \mathrm{~L}$ Tedlar bags and analyzed using SRI gas chromatograph with TCD and HID detector to validate the $\mathrm{CO}_{2}$ and $\mathrm{CH}_{4}$ composition. The results of the pressure swing adsorption (PSA) experiments showed an average increase of $160 \%$ in the net heating value over that of a certified gas standard. The amount of methane was also significantly higher although the amount of the other gasses (i.e. nitrogen) remained comparatively the same. The number of other gases was significantly lower and leaving no traces of carbon dioxide was observed in the PSA system product gas indicating that carbon dioxide had been completely adsorbed by the system. This study greatly helps to reduce $\mathrm{CO}_{2}$ emitted to the atmosphere from the anaerobic co-digestion of biogas to produce high energy content bio-methane fuel.
\end{abstract}

\section{Introduction}

Biogas technology has been developed and widely used over the world because it has several advantages - the reduction of the dependence on non-renewable resources, high energy-efficiency, environmental benefits, available and cheap resources to feedstock, relatively easy and cheap technology for production, and additional values of digestate as a fertilizer.

Biogas as one of the sources of renewable energy significantly due to some ecological advantages, mainly being $\mathrm{CO}_{2}$ as neutral; hence, it reduces greenhouse gas formation. Further, biogas production minimized the waste disposal as agricultural, commercial and municipal waste from anthropogenic sources.

Biogas mainly comprises methane (40-75\%) and carbon dioxide $(20-55 \%)$, and trace components of hydrogen sulfide $\left(\mathrm{H}_{2} \mathrm{~S}\right)$, ammonia $\left(\mathrm{NH}_{3}\right)$ and siloxanes. This trace components may destroy the engine, e.g., due to corrosion [1]-[2]. Removing the impurities leads to higher the amount of methane, the higher the output of energy from biogas.

There are technologies commercially available for removal of $\mathrm{CO}_{2}$ from biogas are typically used for applications such as gas wells, sewage treatment plants, and landfills. Because of the different contaminants, there are processes that can be considered for $\mathrm{CO}_{2}$ removal from biogas such as pressure swing adsorption, using of amines, vacuum swing adsorption, among others.

A Pressure Swing Adsorption (PSA) processes separate out $\mathrm{CO}_{2}$, oxygen, and nitrogen by absorption and desorption on activated carbon at different pressures in four stages - adsorption, depressurizing, desorption and pressure build up. The principle of the pressurized process as described by Santos, et. al, 2010 [3] more readily dissolved in activated carbon than methane. Their proposed biogas upgrading plant presented in their research of Santos, et. al, 2010 [3] consists of a scrubber vessel for scrubbing (absorption of $\mathrm{CO}_{2}$ into adsorbent like activated carbon), a flash tank for methane gas recovery, and a desorption tower for the regeneration.

In Pressure Swing Adsorption (PSA) processes, the absorbent is used as a medium to remove selectively the carbon dioxide gas. The adsorbent is a porous solid, normally with a high surface area.

Among those absorbents, zeolite, activated carbon, carbon molecular sieves (CMS) but also activated carbons, zeolites and other materials (titanosilicates) are used commercially. However, using these Zeolite has encountered difficulty to the adsorption properties to the chemical composition of the surfaces as identified by Siriwardane et.al, (2001) [4]. Moreover, Wang and Levan (2009) [5] measures the adsorption Isotherms for pure water vapor and carbon dioxide on zeolites over a wide of temperatures and the adsorption results to

\footnotetext{
* Corresponding author: a_magomnang@yahoo.com
} 
confirmed their isotherm model used. Aside from that, Konduru, et. al (2007) [9] studied Zeolite 13X regeneration and recovery efficiency and suggests the determination of the optimum system parameters in order to establish that Zeolite $13 \mathrm{X}$ is the best absorbent. Hauchhum and Mahanta (2014) [6], also suggests that extensive study on the regeneration capability on Zeolite $4 \mathrm{~A}$ and $13 \mathrm{X}$.

From all the technologies presented, the pressure swing adsorption method of $\mathrm{CO}_{2}$ removal was chosen because of the capability of its material presents stronger surface interactions to $\mathrm{CO}_{2}$, to adsorb larger loadings as compared to methane [3]. This also supported by the study of Hauchhum \& Mahanta, 2014 [6] showing a promising option to separate $\mathrm{CO}_{2}$ due to its ease of applicability over a wide range of temperature and pressure conditions, also, it's low energy requirements and its low capital investment.

Based on the studies and gaps presented, this study contributes on assessing and determining the optimum system parameters required for zeolite $13 X$ as an adsorbent in removing the carbon dioxide from biogas as a renewable source of fuel. After removal of the carbon dioxide, the methane gas then is used for possible engine testing in a stationary non-road engine. This technology overcomes the problem in increasing the methane recovery from biogas upgrading.

Thus, this study aims to evaluate the performance parameters of a Pressure Swing Adsorption (PSA) unit in removing the carbon dioxide from biogas by evaluating the breakthrough and adsorption capacity of the adsorption process as well as determining the effects of cyclic regeneration of the adsorbent from the anaerobic co-digestion of agricultural biomass waste utilizing dairy manure co-digested with various biomass feedstocks for power generation applications.

\section{Materials and methods}

\subsection{Biogas upgrading experimental conditions}

An experimental set-up is created only for the removing carbon dioxide $\left(\mathrm{CO}_{2}\right)$ from biogas. Wherein, a representative gas mixture, comprised of $63.18 \% \mathrm{vol}$. $\mathrm{CH}_{4}$ and $36.82 \%$ vol. $\mathrm{CO}_{2}$ will be passing through the adsorbent bed in an up-flow motion. After, pure methane in a down-flow motion in order to regenerate the adsorbent [7]. For this study, the researcher aims to compare the effects on the adsorption of using Zeolite 13X (Molecular Sieve) for the removing of carbon dioxide $\left(\mathrm{CO}_{2}\right)$ from a representative biogas mixture.

The experiments were conducted using a certified gas mixture standard prepared by Airgas (Airgas Southwest, Woodlands TX). This gas mixture is a good representation of the biogas produced from anaerobic codigestion processes. For this experiment, the pressure was set at $400 \mathrm{kPa}$ and the product gas outlet flow rate at 0.5-1.0 LPM. The product gas was also analyzed in real time using the Horiba NDIR gas analyzer and simultaneously analyzed using SRI gas chromatograph
(SRI Instruments, Torrance, CA) with TCD and HID detector to validate the $\mathrm{CO}_{2}$ and $\mathrm{CH}_{4}$ composition.

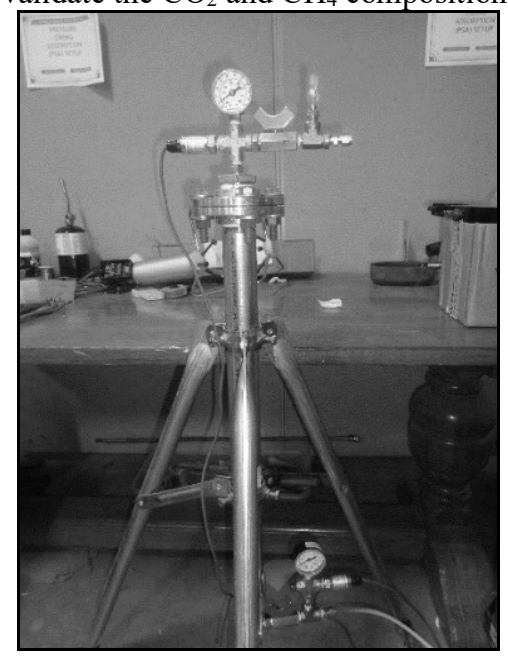

Fig. 1. Pressure Swing Adsorption Unit Schematic Diagram

\section{$2.2 \mathrm{CO}_{2}$ adsorption studies}

Mérel, et.al, 2006 [8] described Pressure Swing Adsorption (PSA), working between high-pressure level during adsorption and a low-pressure level for desorption. Further, the study of Mérel, et.al, 2006 [8] employed the basic sequence of steps, referred to as the skarkstorm cycle, consist of pressurization, followed by adsorption and depressurization (blown down) followed by a purge or evacuation of the highly adsorbed component. On this study, the simple skarkstorm fourstep cycle used and selected as the baseline because of the simplicity of the processes.

The removal of carbon dioxide on this study are operated with four steps: pressurization, adsorption, depressurization, and desorption. During the pressurization, gas representing the biogas composition consisting of $63.18 \% \mathrm{CH}_{4}$ and $36.82 \% \mathrm{CO}_{2}$ at ambient temperature is supplied to the bottom of the bed. During the adsorption, carbon dioxide $\left(\mathrm{CO}_{2}\right)$ is adsorbed on Zeolite $13 \mathrm{X}$, where methane $\left(\mathrm{CH}_{4}\right)$ is obtained as product gas and the high-pressure feed gas enters in the pressurization step.

\subsubsection{Breakthrough experiments}

The Breakthrough curve will be determined and plotted in Fig. 2. For simplicity, a representative mixture of $63.18 \% \mathrm{CH}_{4}$ and $36.82 \% \mathrm{CO}_{2}$ represented in a typical biogas composition were assumed in this analysis.

\subsubsection{Regeneration and reusability of the zeolite $13 X$ at room temperature}

Out of the adsorbent studied, zeolite $13 \mathrm{X}$ showed the optimal adsorption capacity of the zeolite $13 \mathrm{X}$ adsorbent is at $30^{\circ} \mathrm{C}$. Therefore, Zeolite $13 \mathrm{X}$ were studied for reusability with free-flowing air desorption at room temperature in the same run followed by vacuum purge. 
In the same manner, Jadhav, et.al, 2007 [10] reported that the adsorbent successfully retained adsorption capacity in three consecutive reuse cycles. The slight loss of capacity after the first cycle probably owing to some irreversible adsorption that could have been desorbed at ambient temperature.

\subsubsection{Selectivity studies}

The selectivity of the zeolite $13 \mathrm{X}$ adsorbents on the removal of carbon dioxide was studied using a mixture of $63.18 \%$ vol. of $\mathrm{CH}_{4}$ and $36.82 \%$ vol. of $\mathrm{CO}_{2}$ of biogas prepared by setting the flows around $0.63 \mathrm{l} / \mathrm{min}$. prior to the adsorbent study, the adsorbent was preweighted and placed in the PSA unit. The mixture then flowed over the Zeolite 13X, and the product gas was gathered using the Horiba NDIR gas analyzer.

\section{Results and discussions}

\section{$3.1 \mathrm{CO}_{2}$ upgrading system evaluation}

\subsubsection{Breakthrough experiments}

Hauchhum and Mahanta, 2014 [6] defined Adsorption as "a transient process and the amounts of material adsorbed within a fixed bed will depend on both position and time".

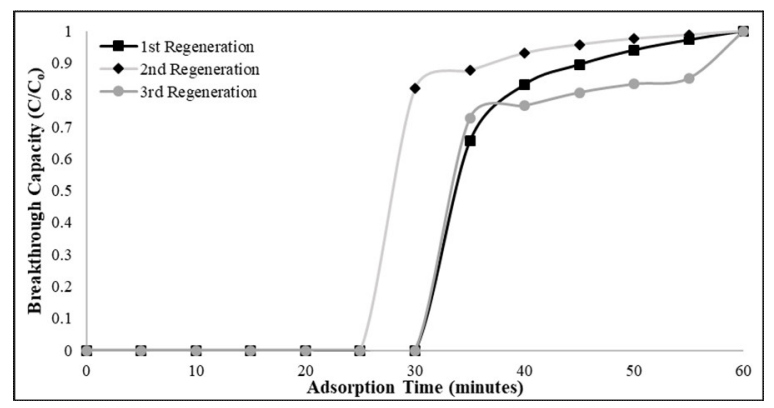

Fig. 2. Breakthrough curve for carbon dioxide $\left(\mathrm{CO}_{2}\right)$ removal using zeolite $13 \mathrm{X}$ at $400 \mathrm{kPa}$ pressure

The $\mathrm{CO}_{2}$ breakthrough curves for the zeolite $13 \mathrm{X}$ is shown in Fig. 2, and the experimental conditions are a binary gas mixture represented in a typical biogas composition is assumed in this analysis. Further, Hauchhum \& Mahanta, 2014 [6] represents breakthrough curves as the ratio of the outlet concentration and the influent concentration against the contact time at an atmospheric pressure, and at some temperatures. For zeolite 13X, the adsorption experiencing breakthrough around $25-35$ minutes depending on the efficiency of desorption (regeneration) of the adsorbent.

This implies that change in pore diameter of the adsorbent, zeolite $13 \mathrm{X}(10 \AA)$ plays a vital role in entering the zeolite channels. Also, their cations, which is $\mathrm{Na}$ and $\mathrm{K}$ also helps in the adsorption of carbon dioxide. Due to its larger pore volume, zeolite $13 \mathrm{X}$ saturation is longer. In addition, the difference in chemical composition and nature of the surface and porosity was observed during the adsorption. Since the zeolite $13 \mathrm{X}$ has higher surface area can contribute to the higher adsorption capacity of zeolites, as compared with the study of Hauchhum and Mahanta, 2014 [6].

Furthermore, the reported values of carbon dioxide adsorption are in agreement with the published data of Hauchuum and Mahanta, 2014 [6], although the reported values of amount adsorbed are higher than all previous literature. In low-pressure range, the amount adsorbed compares very well with the data reported by [6].

\subsubsection{Effects on reusability of adsorbent}

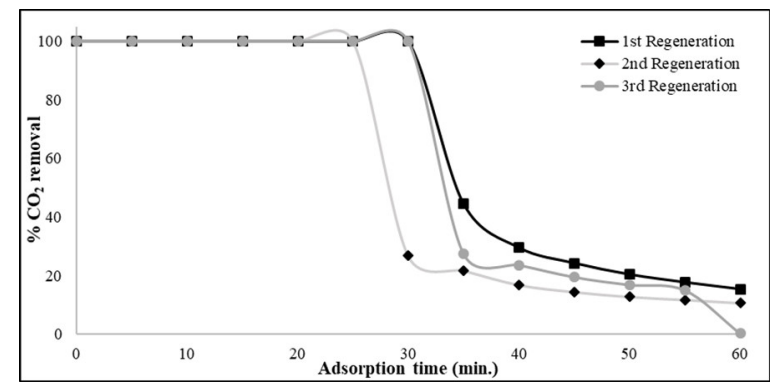

Fig. 3 Percentage removal of $\mathrm{CO}_{2}$ sorption at different regeneration cycles

The adsorption capacity of the zeolite $13 \mathrm{X}$ indicates the reusability (regeneration capacity) of the adsorbent as presented in Fig. 3. Based on the experimental results, a $100 \%$ removal of carbon dioxide from the biogas is maintained after some time and the zeolite can be reused by passing through a countercurrent flow of air.

However, removal (desorption) efficiency of zeolite decreases every time it regenerates and it implied that the zeolite is not completely regenerated by air. This issue will be addressed by introducing hot air during the regeneration process.

\subsubsection{Adsorption kinetics and contact time studies}

The effluent concentration of the $\mathrm{CH}_{4}-\mathrm{CO}_{2}$ gas mixtures dropped to zero $\mathrm{ppm}_{\mathrm{v}}$ for approximately $26-33$ minutes at initial capacity is $22.5 \mathrm{~g}_{\mathrm{CO} 2} / \mathrm{kg}_{\text {Zeolitel3X. These results }}$ are slightly lower than the reported values of by Konduru, et. al, 2007 [9], for a gas mixture containing $\mathrm{N}_{2}(75 \%)$ and $\mathrm{CO}_{2}(25 \%)$.

The experimental results were expected as dismal since the gas mixture is different $\left(63.18 \% \mathrm{CH}_{4}\right.$ and $36.82 \% \mathrm{CO}_{2}$ ) from related studies. Also, adsorption was terminated prior to the complete saturation due to instrumentation limitations. Moreover, Figure 4 shows the time required in reaching the saturation capacity decreases with each regeneration cycle. These results attributed to the residual (remaining) $\mathrm{CH}_{4}-\mathrm{CO}_{2}$ mixture were not removed during the regeneration cycle.

The adsorption isotherms of breakthrough and carbon dioxide adsorption were shown in Fig. 4. Based on the results, indicated in Figure 4 the adsorption of zeolite $13 \mathrm{X}$ is fully reversible and complete regeneration 
can have done and obtainable by evacuation of the adsorbent after adsorption process.

In addition, final adsorption curve shown with $\mathrm{CO}_{2}$ was similar with Mérel, et. al, 2006 [8] and it indicates adsorbent was not affected by the adsorption of methane $\left(\mathrm{CH}_{4}\right)$ even after third regeneration. These results suggest that separation of carbon dioxide of carbon dioxide from a $\mathrm{CH}_{4}-\mathrm{CO}_{2}$ mixture is possible with Zeolite-13X adsorbents.

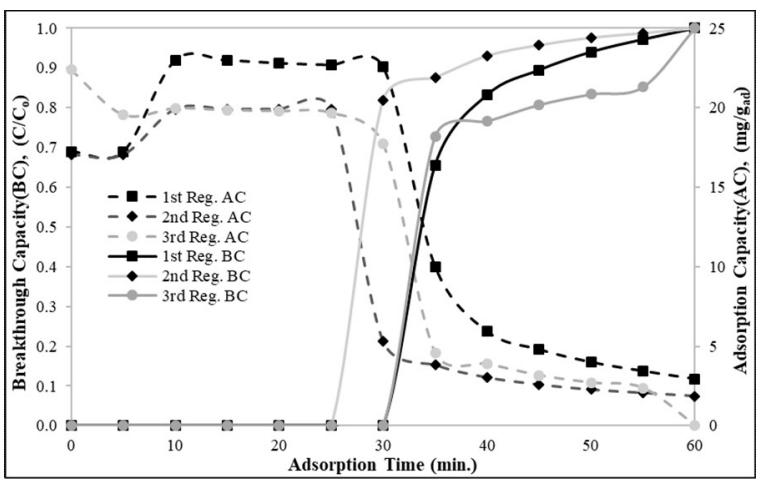

Fig. $4 \mathrm{CO}_{2}$ sorption isotherms of Breakthrough and Adsorption Capacity at different regeneration cycles

\subsubsection{Selectivity studies}

As shown in Figure 4, $\mathrm{CO}_{2}$ adsorption breakthrough occurred around 25-30 minutes of adsorption, until the maximum adsorption capacity of the zeolite $13 \mathrm{X}$ was spent.

As reported by Jadhav, et.al (2007) [10], that the adsorption capacity of the zeolite $13 \mathrm{X}$ is found to be higher for $\mathrm{CO}_{2}$ than for $\mathrm{CH}_{4}$ [8]. As compared with the saturation adsorption capacities of Zeolite $13 \mathrm{X}$ for $\mathrm{CO}_{2}$ and $\mathrm{CH}_{4}$ are for this experiment are $(22.50,19.92$ and $17.74 \mathrm{mg} / \mathrm{g}_{\text {ads }}$ ) respectively.

Thus, $\mathrm{CH}_{4}$ breakthrough shows a bulge or hump of $(\mathrm{C} / \mathrm{Co}>1)$ as reported by Jadhav, et. al, 2007 [10]. This implies that competitive adsorption of carbon dioxide from biogas was taking place [10]. Since $\mathrm{CH}_{4}$ being in higher concentration occupies more sites and kinetic selectivity for $\mathrm{CO}_{2}$ plays a vital role that the adsorbed $\mathrm{CH}_{4}$ is displaced making space for $\mathrm{CO}_{2}$. Thus, the product gas values of $\mathrm{CH}_{4}$ shows an increase of values over than in the inlet.

\section{Conclusion}

The results of the PSA experiments showed an average increase of $160 \%$ in the net heating value over that of the certified gas standard. The amount of methane was also significantly higher although the amount of the other gasses (i.e. nitrogen) remained comparatively the same. The quantity of carbon monoxide $\left(\mathrm{CO}_{2}\right)$ in the product gas was significantly lower and no traces of carbon dioxide was observed in the PSA product gas indicating that carbon dioxide had been completely adsorbed by the system. The raw gas inlet flow rate started at $0.71 \mathrm{LPM}$ and ended at around 0.80 LPM until the vessel was regenerated in a countercurrent of air. Based on the product gas composition during the adsorption and desorption cycles, the desired concentration of the product gas was achieved in a short span of 1 minute during adsorption. A longer stable gas concentration may be achieved by using more adsorbent.

The authors would like to thank the DOST-PCIEERD for providing financial assistance for the International Conference presentation. Also, the Bio-Energy Testing and Analysis Laboratory of Texas A\&M University, College Station, Texas, USA for offering me the opportunity to conduct this research. Likewise, the Engineering Research and Development for Technology (ERDT) under the Science Education Institute (SEI) of Department of Science and Technology in the Philippines, and the College of Engineering and Architecture, USTSP-CDO for their support to this research presentation.

\section{References}

1. Biogaszusamensetzung (Composition of biogas), Available from https://bit.ly/2zblhl4. Date Accessed: 01/21/2018.

2. M. Harasimowicz, P. Orluk, G. ZakrzewskaTrznadel, AG Chmielewski. Application of polyimide membranes for biogas purification and enrichment. Journal of Hazardous Materials. 144 (3), (2007).

3. M.P. Santos, C.A. Grande, A.E. Rodrigues. Pressure swing adsorption for biogas upgrading. Effect of recycling streams in pressure swing adsorption design. Industrial \& Engineering Chemistry Research. 50(2), (2010).

4. R.V. Siriwardane, M.S.Shen, E.P. Fisher, and J.A.Poston. Adsorption of $\mathrm{CO} 2$ on molecular sieves and activated carbon. Energy \& Fuels, 15(2); (2001).

5. Y. Wang, and M.D.LeVan. Adsorption equilibrium of carbon dioxide and water vapor on zeolites $5 \mathrm{~A}$ and $13 \mathrm{X}$ and silica gel: pure components. Journal of Chemical \& Engineering Data, 54(10); (2009).

6. L. Hauchhum, P. Mahanta. Carbon dioxide adsorption on zeolites and activated carbon by pressure swing adsorption in a fixed bed. International Journal of Energy and Environmental Engineering. 5(4), (2014)

7. A.L. Maglinao, S.C. Capareda, H. Nam. Fluidized bed gasification of high tonnage sorghum, cotton gin trash and beef cattle manure: evaluation of synthesis gas production. Energy Conversion and Management. 105 (2015).

8. J. Mérel, M. Clausse, F. Meunier. Carbon dioxide capture by indirect thermal swing adsorption using 13X zeolite. Environmental Progress \& Sustainable Energy. 25(4), (2006).

9. N. Konduru, P. Lindner, N.M. Assaf-Anid. Curbing the greenhouse effect by carbon dioxide adsorption with zeolite 13X. AIChE journal. 53(12). (2007).

10. P.D. Jadhav, R.V. Chatti, R.B. Biniwale, N.K. Labhsetwar, S. Devotta, S.S. Rayalu, Monoethanol amine modified zeolite $13 \mathrm{X}$ for $\mathrm{CO}_{2}$ adsorption at different temperatures. Energy \& Fuels. 21(6); (2007). 